\title{
Therapeutic Path of Dental Expertise in Obstructive Sleep Apnea Syndrome (OSAS)
}

\author{
Antonio Crispino $^{1}$, Vincenzo Crispino ${ }^{2}$, Luigi Crispino², Lucia Valentino ${ }^{3}$, Leonzio Fortunato ${ }^{1}$ \\ ${ }^{1}$ Schoolod Dentistry, University of Catanzaro, Catanzaro, Italy \\ ${ }^{2}$ Private Practice, Agropoli (SA), Italy \\ ${ }^{3}$ Magna Graecia Institute, Dental Research Center, Catanzaro, Italy \\ Email: crispino@unicz.it, studiomedicocrispino@gmail.com,crispinomedicolegale@libero.it, lvalentino983@gmail.com, \\ fortunato@unicz.it
}

How to cite this paper: Crispino, A., Crispino, V., Crispino, L., Valentino, L. and Fortunato, L. (2018) Therapeutic Path of Dental Expertise in Obstructive Sleep Apnea Syndrome (OSAS). Modern Research in Inflammation, 7, 1-8.

https://doi.org/10.4236/mri.2018.71001

Received: November 4, 2017

Accepted: February 2, 2018

Published: February 5, 2018

Copyright $\odot 2018$ by authors and Scientific Research Publishing Inc. This work is licensed under the Creative Commons Attribution International License (CC BY 4.0).

http://creativecommons.org/licenses/by/4.0/

\begin{abstract}
Obstructive Sleep Apnea Syndrome (OSAS) is a respiratory sleep disorder characterized by repeated episodes of complete or partial obstruction of the upper airway. OSAS has a frequency of 4 percent and is classified according to the number of obstructive sleep apnea-hypopnea episodes. The OSAS diagnostic path starts with the evaluation of the patient's clinical framework and follows an instrumental procedure, depending on the clinical severity of the patient. Dental practitioners have the ability to intercept early on the signs and symptoms of OSAS. At the same time, they can assess whether the patient has the indications for treatment with specific oral devices (Oral Appliances, $\mathrm{OA})$. The purpose of this paper is to provide guidance for dental management of obstructive sleep apnea syndrome in adult individuals.
\end{abstract}

\section{Keywords}

Obstructive Sleep Apnea, Sleep Evaluation, Positive Airway Pressure Treatment, Oral Appliance Treatment

\section{General overview}

Obstructive sleep apnea syndrome (OSAS) is a respiratory sleep disorder characterized by repeated episodes of complete (apnea) or partial (hypopnea) obstruction of the upper airway, with reductions in the rate of saturation of the obstructive sleep apnea, arterial oxygen and possible increase in blood carbon dioxide [1]. Repeated apnea and hypopnea induce a respiratory effect with possible heart rate variations, sleep fragmentation and increased pulmonary and systemic blood pressure values [1] [2]. 
The night-time symptoms that characterize OSAS include: habitual snoring, respiratory sleeping in partner-related sleep, awaken with choking sensation, night-sleepiness, nicturia, xerostomia and, to a lesser extent, excessive night sweats.

The day-to-day effects of OSAS are: non-restorative sleep feeling, headache, excessive daytime sleepiness, increased risk of road accidents (3.5 to 8 times greater than the control population), cognitive deficits (in particular memory disorders, concentration and attention) and, to a lesser extent, depression of the tone of mood and sexual impotence [3].

It is estimated 30 percent of Russian adults habitually; this percentage increases in the population around the age of 60 , to affect about 60 percent of men and 40 percent of women.

The snoring symptom, understood as a simple and isolated noisy manifestation during sleep, without association with other symptoms (e.g. apnea), is a social problem for the individual but has no significant clinical relevance. However, snoring is a phenomenon that cannot and should not be underestimated, as it always precedes and is present in almost all subjects affected by OSAS. In light of this consideration, a simple general screening of the population of regular russors can be helpful in detecting patients with OSAS, a syndrome that is currently being diagnosed and treated only in a small part of the existing cases [4].

OSAS has a frequency of 4 percent and is classified according to the number of obstructive apnea-hypopnea episodes per hour of sleep; very commonly used is the Apnea-Hypopnea Index (AHI) which defines mild OSAS with an AHI between 5 and 15, moderate OSAS between 16 and 30 and severe OSAS if greater than 30 . However, the respiratory rate index alone does not determine the clinical picture of OSAS, as it is also necessary to consider the levels of night hypoxia achieved and the associated complications and/or associated risk factors [5] [6].

In patients with OSAS, depending on the size of the pathological picture (apnea duration and relative desaturation percentage), sleep may be fragmented with partial awakening which the patient is unaware of. In this way, apnea does not allow the achievement of restful sleep and causes drowsiness in the daytime. Reduced sleep quality, with daytime sleepiness, is associated with performance alterations, decreased concentration, irritability and, in more severe cases, with a true psychomotor slowdown [7] [8]. All of these factors severely affect the quality of life of the patient and are intended to evolve toward more serious clinical frameworks, characterized by the increased chance of emergence of pathologies such as systemic hypertension, ischemic heart disease, heart attack, pulmonary hypertension, and heart arrhythmias [9] [10].

\section{Diagnostic Path}

The OSAS diagnostic path starts with the evaluation of the patient's clinical framework and follows an instrumental procedure, depending on the clinical severity of the patient [11] [12]. The instrumental procedure, generally called 
polysomnography, actually consists of several types of monitoring, whose paths must always be manually analyzed by a physician experienced in sleep disturbances. They consist of:

1) Reduced cardiorespiratory night vision;

2) Complete cardiorespiratory night monitoring;

3) Night polysomnography with portable system;

4) Laboratory night polysomnography.

\section{Role of the Dentist}

A very high percentage of the general population goes to the dentist at least once a year for inspection visits, professional oral hygiene or therapies. For this reason, dental practitioners have the ability to intercept early on the signs and symptoms of OSAS. At the same time, they can assess whether the patient has the indications for treatment with specific oral devices (Oral Appliances, $O A$ ) [13].

It is important for the dentist to know and share with the patient the various therapeutic approaches to OSAS such as medical therapy, the use of Continuous Positive Airway Pressure (CPAP), and the surgical therapy of oropharyngeal or repositioning of the jawbones.

Medical therapy aims at eliminating predisposing factors in the onset of OSAS or snoring [14].

In people overweight or obese, the build-up of adipose tissue in the subomalic region and in the back-pharyngeal spaces contributes to reducing the airway caliber. Weight loss can, in these subjects, lead to symptomatic improvements to a complete remission [15].

Slimming can be obtained with an appropriate diet combined with proper motor activity; in overweight or poorly-performing patients, with gastro-intestinal or intestinal bypass surgery.

Another non-invasive approach to the problem is sleep hygiene counseling, suggestions on the position to be taken during sleep and behavioral changes such as abstinence in alcohol intake (especially in the evening), smoking and drug depressors in the system central nervous. In the most severe cases, using a specialist's collaboration, it is possible to administer drugs to decongestion and lubricate the airways, to increase the speed and depth of breathing, or drugs that inhibit REM sleep [16].

First Aperture Ventilation (CPAP) promotes regression of symptomatology with a clear reduction in HAI. Even though it represents an important aid to the care of OSAS, however, it is poorly tolerated by patients given the bulk and noise of the equipment.

Surgical therapy aims, instead, to remove obstructive respiratory factors in anatomic districts of otolaryngology.

With oropharyngeal surgery, the stiffening and remodeling of the muzzle of the mouths is obtained both at the level of the palatine tonsils and in the region 
of the palatine veil. Hypopharyngeal surgery, however, has the purpose of expanding the rear air space by reducing the volume of the lingual base.

The particularly important, for the treatment of OSAS, is ultimately maxillomandible maxillo-maxillary surgery (bimbolic osteotomy) [17].

\section{Therapeutic Path of Dental Expertise}

Dental surgery, complete with the diagnostic route, can provide, where appropriate, the application of an Oral Appliances (OA).

The choice of the OA to be applied is conditioned by various factors such as comfort, ease of use, editable mandibular advance and mandibular motion ability.

With the same characteristics, the choice of the device can be handed over to the patient.

Choosing the most powerful OA, you need to detect archery impressions, even with digital technologies [18].

Very important is the choice of "bite construction" that will determine the therapeutic position of the jaw with the OA inserted in the oral cavity.

The standard recording is taken to approximately $50 \%-70 \%$ of the maximum protrusion obtainable by the patient. If an editable device is used, the protrusion chosen with the construction bite will be a starting point for increasing or, if necessary, decreasing the mandible advancement [19].

When the device is delivered to the patient, instructions are required for its use. It is important that the appliance is as comfortable as possible when worn at night; for this reason it is preferable to use it for a few hours during the day for a week, before night time, to achieve optimal adaptation.

When delivering the appliance, it is necessary to find the optimal mandibular advance. At this stage, it is crucial to find the right balance between the effectiveness of the propulsion and any side effects: in practice, it is important to achieve maximum comfort for the patient in which the mandibular protrusion is in the absence of a musculoskeletal algorithm or ATM. In this respect, it should be emphasized that, in the case of non-reducible displacement of the ATM, it is convenient not to advance the jaw but to use the oral device in simple closure.

To check the effectiveness of OA, it is strongly advised that the patient should carry a daily report on the strength of the snoring reported by the partner, whether there is tiredness on the awakening and drowsiness. By comparing data with those recorded before treatment, it may be necessary to further increase mandibular advance [20].

Once the optimal mandibular advance level is clinically established by the OA, a polysomal control study with OA's simultaneous application is programmed to establish efficacy and document the results.

In the absence of resolution of the disease it is important to send the patient to the specialist in treating sleep disorders [21]. 


\section{Oral Appliances (OA)}

OA therapy represents the treatment method for OSAS that has had the greatest development in recent years and clinical efficacy has been demonstrated by a large number of clinical and instrumental researches.

These devices maintain the reticence of the airways behind the tongue, moving forward and/or keeping the mandible closed and increasing the vertical occlusion size. Thus, there is a progression of the tongue, an increase in the tension of the pharyngeal walls, and the impossibility of post-rotating mandible, so as to prevent partial or total occlusion of the respiratory flow [22].

OA act both at the level of the retrooping and retrograde region, with an effect on the transverse and sagittal dimension.

The type of equipment available has evolved over time and the OA currently used are more comfortable, less bulky and more tolerant than those produced in the past. In addition, some side effects caused by these devices have proved less important than they feared in the past [23].

Despite the effectiveness of ventilatory therapy with CPAP is greater in reducing respiratory obstruction rates, $\mathrm{OA}$ are generally better tolerated by the patient. Consequently, they are recommended at international level for a larger number of cases than in the past, a statement demonstrated by the evolution of the American Academy Sleep Medicine Guidelines from 1995 to 2005 and 2009 [24].

The dentist must know the indications and contraindications of OSAS treatment with both CPAP and maxillo-mandibular advance, so that the patient can be directed to the maxillo-facial surgeon when appropriate.

The dentist must be prepared to handle treatments combined with OA and otorhinolaryngology surgery or with OA and CPAP if it is necessary to reduce effective pressure [25].

A careful preliminary assessment of the condition of the oral mucosa, teeth, periodontal structures and mouth function, with particular regard to chewing muscles, temporomandibular articulations, and the presence of malocclusion and dysgenesis is advised to verify the possibility of use of OA in the patient.

The choice of the device is the sole responsibility of the dentist who has to consider the particularity of the case and its specific knowledge. It is recommended to extend this knowledge to different types of $\mathrm{OA}$, since no device is ideal for all patients [26].

\section{Conflicts of Interests}

All authors agree with the content of the manuscript and there are no conflicts of interests between them.

\section{References}

[1] Mbata, G.C. and Chukwuka, J.C. (2012) Obstructive Sleep Apnea Hypopnea Syndrome. Annals of Medical \& Health Sciences Research, 2, 74-77. 
[2] Lee, W.H., Wee, J.H., Lee, C.H., Kim, M.S., Rhee, C.S., Yun, P.Y., Yoon, I.Y. and Kim, J.W. (2013) Comparison between Mono-Bloc and Bi-Bloc Mandibular Advancement Devices for Obstructive Sleep Apnea. European Archives of Oto-RhinoLaryngology, 270, 2909-2913. https://doi.org/10.1007/s00405-013-2417-0

[3] Gagnadoux, F., Fleury, B., Vieille, B., Meslier, N., N'Guyen, X.L., Trzepizur, W. and Racineux, J.L. (2009) Titrated Mandibular Advancement versus Positive Airway Pressure for Sleep Apnea. European Respiratory Journal, 34, 914-920. https://doi.org/10.1183/09031936.00148208

[4] Randerath, W.J., Verbraecken, J., Andreas, S., Bettega, G., Boudewyns, A., Hamans, E., Jalbert, F., Paoli, J.R., Sanner, B., Smith, I., Stuck, B.A., Lacassagne, L., Marklund, M., Maurer, J.T., Pepin, J.L., Valipour, A., Verse, T. and Fietze, I. (2011) European Respiratory Society Task Force on Non-CPAP Therapies in Sleep Apnea. NonCPAP Therapies in Obstructive Sleep Apnea. European Respiratory Journal, 37, 1000-1028. https://doi.org/10.1183/09031936.00099710

[5] Cistulli, P.A., Gotsopoulos, H., Marklund, M. and Lowe, A.A. (2004) Treatment of Snoring and Obstructive Sleep Apnea with Mandibular Repositioning Appliances. Sleep Medicine Reviews, 8, 443-457. https://doi.org/10.1016/j.smrv.2004.04.002

[6] Deane, S.A., Cistulli, P.A., Ng, A.T., Zeng, B., Petocz, P. and Darendeliler, M.A. (2009) Comparison of Mandibular Advancement Splint and Tongue Stabilizing Device in Obstructive Sleep Apnea: A Randomized Controlled Trial. Sleep, 32, 648653. https://doi.org/10.1093/sleep/32.5.648

[7] Stradling, J. and Dookun, R. (2009) Snoring and the Role of the GDP: British Society of Dental Sleep Medicine (BSDSM) Pre-Treatment Protocol. British Dental Journal, 206, 307-312. https://doi.org/10.1038/sj.bdj.2009.214

[8] National Guidelines for Prevention and Odontoiatric Treatment of Obstructive Sleep Apnea Syndrome (OSAS). Ministry of Health, General Directorate for Health Prevention, Italy, 2014.

[9] Sil, A., Barr, G., Marin, J.M., Agusti, A., Villar, I., Forner, M., Nieto, D., Carrizo, S.J., Barbé, F., Vicente, E., Wei, Y., Nieto, F.J. and Jelic, S. (2012) Assessment of Predictive Ability of Epworth Scoring in Screening of Patients with Sleep Apnea. The Journal of Laryngology \& Otology, 126, 372-379. https://doi.org/10.1017/S0022215111003082

[10] Dort, L. and Brant, R. (2008) A Randomized, Controlled, Crossover Study of a No Customized Tongue Retaining Device for Sleep Disordered Breathing. Sleep and Breathing, 4, 369-373. https://doi.org/10.1007/s11325-008-0187-5

[11] Epstein, L.J., Kristo, D., Strollo Jr., P.J., Friedman, N., Malhotra, A., Patil, S.P., Ramar, K., Rogers, R., Schwab, R.J., Weaver, E.M. and Weinstein, M.D. (2009) Adult Obstructive Sleep Apnea Task Force of the American Academy of Sleep Medicine. Clinical Guideline for the Evaluation, Management and Long-Term Care of Obstructive Sleep Apnea in Adults. Journal of Clinical Sleep Medicine, 5, 263-276.

[12] Ferguson, K.A., Cartwright, R., Rogers, R. and Schmidt-Nowara, W. (2006) Oral Appliances for Snoring and Obstructive Sleep Apnea: A Review. Sleep, 29, 244-262. https://doi.org/10.1093/sleep/29.2.244

[13] Chan, A.S. and Cistulli, P.A. (2009) Oral Appliance Treatment of Obstructive Sleep Apnea: An Update. Current Opinion in Pulmonary Medicine, 15, 591-596. https://doi.org/10.1097/MCP.0b013e3283319b12

[14] Giannasi, L.C., Almeida, F.R., Nacif, S.R. and de Oliveira, L.V. (2013) Efficacy of an Oral Appliance for the Treatment of Obstructive Sleep Apnea. The International Journal of Prosthodontics, 26, 334-339. https://doi.org/10.11607/ijp.3284 
[15] Hoekema, A., Stegenga, B., Wijkstra, P.J., Van der Hoeven, J.H., Meinesz, A.F. and de Bont, L.G.M. (2008) Obstructive Sleep Apnea Therapy. Journal of Dental Research, 87, 882-887. https://doi.org/10.1177/154405910808700917

[16] Hoffstein, V. (2007) Review of Oral Appliances for Treatment of Sleep-Disordered Breathing. Sleep and Breathing, 11, 1-22.

https://doi.org/10.1007/s11325-006-0084-8

[17] Holley, A.B., Lettieri, C.J. and Shah, A. (2011) Efficacy of an Adjustable Oral Appliance and Comparison with Continuous Positive Airway Pressure for the Treatment of Obstructive Sleep Apnea Syndrome. Chest, 140, 1511-1516. https://doi.org/10.1378/chest.10-2851

[18] Kreivi, H.R., Virkkula, P., Lehto, J.T. and Brander, P.E. (2012) Upper Airway Symptoms in Primary Snoring and in Sleep Apnea. Acta Oto-Laryngologica, 132, 510-518. https://doi.org/10.3109/00016489.2011.644803

[19] Friedman, M., Hamilton, C., Samuelson, C.G., Kelley, K., Pearson-Chauhan, K., Taylor, D., Taylor, R., Maley, A. and Hirsch, M.A. (2012) Compliance and Efficacy of Treatable Thermoplastic versus Custom Mandibular Advancement Devices. Otolaryngology_Head and Neck Surgery, 147, 379-386. https://doi.org/10.1177/0194599812439683

[20] Kushida, C.A., Morgenthaler, T.I., Littner, M.R., Alessi, C.A., Bailey, D., Coleman Jr., J, Friedman, L., Hirshkowitz, M., Kapen, S., Kramer, M., Lee-Chiong, T., Owens, J. and Pancer, J.P. (2006) An American Academy of Sleep Medicine Report. Practice parameters for the Treatment of Snoring and Obstructive Sleep Apnea with Oral Appliances: An Update for 2005. Sleep, 29, 240-243. https://doi.org/10.1093/sleep/29.2.240

[21] Andrèn, A., Sjöquist, M. and Tegelberg, A. (2009) Effects on Blood Pressure after Treatment of Obstructive Sleep Apnea with a Mandibular Advancement Appliance-A Three-Year Follow-Up. Journal of Oral Rehabilitation, 36, 719-725. https://doi.org/10.1111/j.1365-2842.2009.01987.x

[22] Lim, J., Lasserson, T.J., Fleetham, J. and Wright, J. (2006) Oral Appliances for Obstructive Sleep Apnea. The Cochrane Database of Systematic Reviews, 25, CD0044 35.

[23] Dieltjens, M., Vanderveken, O.M., Hamans, E., Verbraecken, J.A., Wouters, K., Willemen, M., De Backer, W.A., Van de Heyning, P.H. and Braem, M.J. (2013) Treatment of Obstructive Sleep Apnea Using a Custom-Made Treatable Duo Bloc Oral Appliance: A Prospective Clinical Study. Sleep and Breathing, 17, 565-572. https://doi.org/10.1007/s11325-012-0721-3

[24] Lettieri, C.J., Paolino, N., Eliasson, A.H., Shah, A.A. and Holley, A.B. (2011) Comparison of Adjustable and Fixed Oral Appliances for the Treatment of Obstructive Sleep Apnea. Journal of Clinical Sleep Medicine, 7, 439-445.

https://doi.org/10.5664/jcsm.1300

[25] Vanderveken, O.M., Devolder, A., Marklund, M., Boudewyns, A.N., Braem, M.J., Okkerse, W., Verbraecken, J.A., Franklin, K.A., De Backer, W.A. and Van de Heyning, P.H. (2008) Comparison of a Custom-Made and a Thermoplastic Oral Appliance for the Treatment of Mild Sleep Apnea. American Journal of Respiratory and Critical Care Medicine, 178, 197-202. https://doi.org/10.1164/rccm.200701-114OC

[26] Woodson, B.T., Steward, D.L., Mickelson, S., Huntley, T. and Goldberg, A. (2010) Multicenter Study of a Novel Adjustable Tongue-Advancement Device for Obstructive Sleep Apnea. Otolaryngology_Head and Neck Surgery, 143, 585-590. https://doi.org/10.1016/j.otohns.2010.06.902 


\section{Abbreviation Note List}

OSAS: Obstructive Sleep Apnea Syndrome;

OA: Oral Appliances;

CPAP: Continuous Positive Airway Pressure. 